\title{
The role of male visual and chemical cues on the activation of female courtship behaviour in the sex-role reversed peacock blenny
}

\author{
D. M. Gonçalves*§, E. N. Barata $\dagger$ t, R. F. Oliveira* and \\ A. V. M. CANÁRIO \\ *Unidade de Investigação em Eco-Etologia, Instituto Superior de Psicologia Aplicada, \\ Rua Jardim do Tabaco 34, 1149-041 Lisboa, Portugal, †Departamento de Biologia, \\ Universidade de Evora, apartado 94, 7002-554 Evora, Portugal and †. Centro de Ciências \\ do Mar, Universidade do Algarve, Campus de Gambelas, 8000 Faro, Portugal
}

(Received 4 January 2002, Accepted 22 May 2002)

\begin{abstract}
Chemical cues during courtship in peacock blenny Salaria pavo did not add significantly to the response of visual stimuli and females did not court when a male was not visible. The results showed that female $S$. pavo courtship behaviour was elicited exclusively by male visual features and not by a multicomponent signal in different sensory modalities. The time spent by females courting the male and exhibiting the nuptial colouration during visual trials correlated with the size of the male's crest, suggesting a signalling function for this trait. Alternative hypothesis for the function of the putative pheromones released by the male's anal gland are discussed. Evidence that female sexual motivation decreases towards the end of the breeding season is also provided, which should be considered in future mate choice experiments.
\end{abstract}

(C) 2002 The Fisheries Society of the British Isles. Published by Elsevier Science Ltd. All rights reserved.

Key words: pheromone; visual cues; chemical cues; Salaria pavo; peacock blenny; multicomponent signals.

\section{INTRODUCTION}

A variety of species use simultaneously more than one sensory channel to communicate. For example, male Jackson's widowbird attract females by leaping into the air above their display site on the ground and simultaneously emitting a call (Bradbury \& Vehrencamp, 1998). Multicomponency increases the efficiency of the signal (Rowe, 1999). Receivers detect, discriminate and memorize multicomponent signals more efficiently than simple signals, and signallers should benefit from producing components in multiple sensory modalities rather than just one (intersensory facilitation; Rowe, 1999).

In this study an investigation was made of whether males of the peacock blenny Salaria pavo (Risso) produce a multicomponent signal to activate female courtship behaviour.

Salaria pavo is a small intertidal fish occurring in the rocky shores of the Mediterranean and adjacent Atlantic coast (Zander, 1986). Males defend nests in crevices or holes and try to attract females to the nest by actively courting them (Patzner et al., 1986). The mating system is promiscuous and only the male

§Author to whom correspondence should be addressed. Tel.: +351218811700; Fax: +351218860954 ; email: davidg@ispa.pt 
takes care of the eggs (Patzner et al., 1986). Males are larger than females and have a well-developed yellowish head crest (Fishelson, 1963; Papaconstantinou, 1979; Patzner et al., 1986). The first two rays of the anal fin are modified into an anal gland that has been suggested to produce and release pheromones that attract females to the males' nests (Laumen et al., 1974; Patzner \& Seiwald, 1987; Zeeck \& Ide, 1996; Barata et al., 2002) and elicit female sexual behaviour (Zeeck $\&$ Ide, 1996). Both the head crest and the anal gland are more developed during the breeding season (Patzner \& Seiwald, 1987; Oliveira et al., 1999) and the development of the anal gland correlates with the maturation of the gonads (Patzner \& Seiwald, 1987).

In the Portuguese population studied a number of interesting features take place. The species occurs in an intertidal mudflat area at the Ria Formosa (southern Portugal) where appropriate nest sites are scarce. Males compete strongly for nests, avoiding leaving the nest and not defending any territory around it (Almada et al., 1994). At the peak of the breeding season almost all nests are fully covered with eggs and females have to compete for the access to the few available spawning sites (Almada et al., 1994). This leads to a reversal of the sex roles, and females have the most active role in courtship, although males also occasionally court females (Almada et al., 1995; Gonçalves et al., 1996). Typically, males stay with the head protruding from the nest and females approach and court the males by quickly flickering the pectoral fins while opening and closing the mouth in synchrony (Patzner et al., 1986; Gonçalves et al., 1996). During courtship episodes females usually display a nuptial colouration consisting of a pattern of alternated vertical dark and light bars in the head and body (Fishelson, 1963; Patzner et al., 1986). Field observations have showed that males often reject courting females, and females also occasionally reject courting males (T. Fagundes, unpubl. data), suggesting that female choice for males is also taking place.

The conspicuous courtship display exhibited by females provides an excellent opportunity to test the function of male secondary sexual ornaments. The male's crest and body marks may provide visual cues to females. Chemical cues provided by the putative pheromones released by the anal gland may act together with the visual component to enhance the detection, discrimination and memorization of males by females. Alternatively, male visual and chemical cues may transmit different information to females in different contexts.

\section{MATERIALS AND METHODS}

\section{FISH}

The animals were collected at Ria Formosa (Algarve, Portugal; 36 $59^{\prime} \mathrm{N} ; 7^{\circ} 51^{\prime} \mathrm{W}$ ) during the breeding season (June-July 1999) and maintained in a controlled photoperiod room (14L : 10D) at the Experimental Station of Ramalhete (Faro, Universidade do Algarve). A total of 40 females and 30 nesting males were captured. Only 24 females (standard length, $L_{\mathrm{S}}$, mean \pm S.E. $=6.3 \pm 1.9 \mathrm{~cm}$, range $4.9-8.4 \mathrm{~cm}$ ) and 12 males $(11 \cdot 1 \pm 0 \cdot 2 \mathrm{~cm}$, range $9 \cdot 9-12.5 \mathrm{~cm})$ were used in the experiment. Fish were kept separately according to sex in groups of five to 10 individuals for males and of 10 to 20 individuals for females. All animals were slightly anaesthetized with MS222, $L_{\mathrm{S}}$ measured and a relative index of crest development calculated by the ratio of head height : body height. Fish were individually marked by fin ray clipping. No infections 


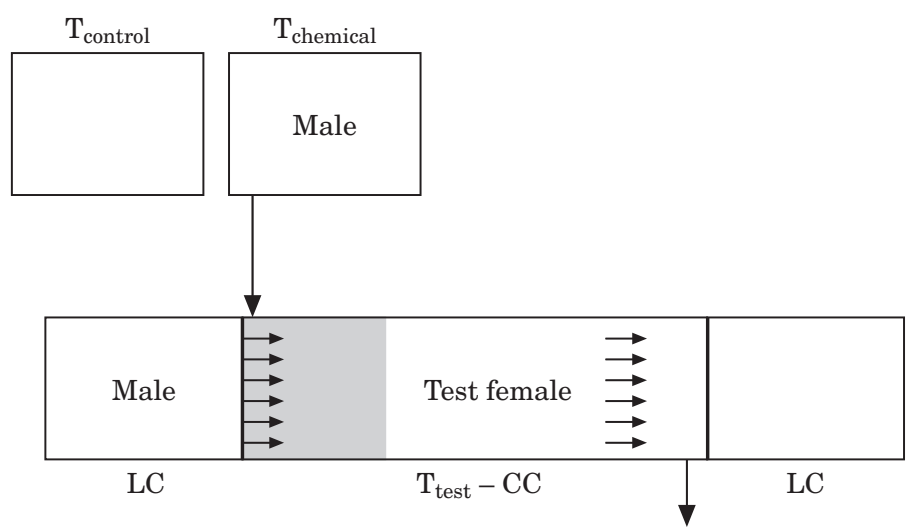

FIG. 1. Diagram of the experimental set up. Treatment CV (chemical+visual) is presented as an example in which a visual (a nesting male) and a chemical (male holding tank water) stimulus were presented simultaneously to test females. $\rightarrow$, direction of water inflow and outflow. $\mathrm{T}_{\text {chemical }}$, tank holding the male source of chemical stimulus; $\mathrm{T}_{\text {control}}$, tank holding control charcoal filtered water; $\mathrm{T}_{\text {test }}$, test tank; LC, lateral compartment; CC, central compartment. Grey area, the 'preference zone'.

were observed in the clipped areas. The stock tanks were $70 \times 40 \times 30 \mathrm{~cm}$ and were covered by a layer of sand and provided with abundant shelters. The animals were fed with frozen common cockles Cerastoderma spp. Only males that defended a shelter in the stock tank were subsequently used in the experiment $(n=12)$. Since males were captured a few days before the experiment, had fully developed secondary sexual traits and were guarding eggs in their nests, it was assumed that they were attractive to females. One hour before being tested females were presented to another nesting male $\left(13.2 \mathrm{~cm} L_{\mathrm{S}}\right)$ and their behaviour recorded. Only females that courted the male were subsequently used $(n=24)$. After the experiment all animals were released into the same place where they were captured and no mortality occurred during captivity.

\section{EXPERIMENTAL SETUP}

The test tank $\left(\mathrm{T}_{\text {test }}\right)$ was $90 \times 15 \times 20 \mathrm{~cm}$ and was divided in two lateral compartments of $20 \mathrm{~cm}$ each and one central compartment of $50 \mathrm{~cm}$ (Fig. 1). The test female was placed in the central compartment and the male used as visual stimulus (treatments $\mathrm{V}$ and $\mathrm{CV}$ ) in one of the lateral compartments. A $15 \mathrm{~cm}$ area adjacent to the stimulus male was defined as the preference zone (Fig. 1), as previous field observations demonstrated that females do not court at a longer distance. Before being tested the female was restricted by two opaque screens to a $20 \mathrm{~cm}$ section in the middle of the central compartment (i.e. a section that excluded the preference zone and an opposite area of similar size) to acclimate to the experimental set up. The central compartment was chemically isolated from the lateral ones by a sealed $3 \mathrm{~mm}$ width glass. A $50 \mathrm{~W}$ halogen lamp placed at c. $25 \mathrm{~cm}$ from the water surface illuminated the lateral compartments. The central compartment was not illuminated. A one-way mirror $(4 \mathrm{~mm}$ width) placed on the inside of the lateral compartments allowed females to see the male used as visual stimulus but not the reverse.

As it was necessary to provide a control water flow in treatment $\mathrm{V}$ that could not pass through the male's compartment, both the water containing the male chemical cues and the control water were provided from separate tanks. Thus, two other tanks of $20 \times 15 \times 20 \mathrm{~cm}$ were used as a source of chemical stimulus $\left(\mathrm{T}_{\text {chemical }}\right)$ and of control water $\left(\mathrm{T}_{\text {control }}\right)$. A mature $S$. pavo male was placed in $\mathrm{T}_{\text {chemical }}$ one day before the test. A continuous water flow of $6 \mathrm{ml} \mathrm{s}^{-1}$ was provided to each of these tanks. Before entering the tanks, water pumped from Ria Formosa was passed through particle and activated charcoal filters to remove uncontrolled impurities. These tanks were placed at a higher position than $T_{\text {test }}$, and water flowed to $T_{\text {test }}$ through a flexible plastic tube $(1.5 \mathrm{~cm}$ 
diameter) connected to one of the two horizontal rigid tubes $(1.2 \mathrm{~cm}$ diameter, $13 \mathrm{~cm}$ length) placed on each bottom-end of the central compartment of $\mathrm{T}_{\text {test }}$. These rigid tubes had six small openings $(3 \mathrm{~mm}$ diameter) providing a water flow parallel to the substratum. The water left the central compartment through an opening $(1.5 \mathrm{~cm}$ diameter) on the top-opposite side of the front wall (Fig. 1). The direction of the water flow throughout the four treatments was always the same for each female.

$\mathrm{T}_{\text {chemical }}, \mathrm{T}_{\text {control }}$ and the lateral compartments of $\mathrm{T}_{\text {test }}$ contained a $15 \mathrm{~cm}$ dark grey plastic tube $(5 \mathrm{~cm}$ diameter $)$ used as a shelter by $S$. pavo stimulus males. The bottom of all tanks were covered by a rigid black plastic structure $(3 \mathrm{~mm}$ thick) and their walls were lined with light brown cardboard to minimize reflections, except for the front glass.

As females occasionally exhibit stress behaviours when they are placed alone in a novel environment (pers. obs.) a fourth tank $\left(\mathrm{T}_{\text {social }}\right)$, adjacent to the central compartment and containing two other females, was used to allow the focal female to interact with conspecifics during the acclimation period. To guarantee that females would be familiarized with the set up and would not spend most of the time in exploratory behaviour during the first experimental trial, they were allowed, before the experiment, to swim freely in the whole central compartment of $T_{\text {test }}$ for 5 min while interacting with females in $T_{\text {social }}$. After this period the female was returned to its stock tank. The central compartment was emptied and thoroughly cleaned with ethanol followed by filtered sea water. The central compartment was refilled, the opaque screens put in place, and the first treatment applied to the same female.

\section{Treatment $V$ : visual}

The male used as a visual stimulus was placed in one of the lateral compartments inside the available shelter. Simultaneously, a test female was introduced in the acclimation area for $5 \mathrm{~min}$. All males adopted the provided shelter during this period and spent most of the time with their head protruding from the shelter, which is also the most common position adopted in the field (pers. observ.). After acclimation light brown cardboard was placed between $T_{\text {social }}$ and $T_{\text {test }}$ so that the behaviours displayed by the focal female during tests were not a result of the interaction with females in $T_{\text {social }}$. The opaque screens were removed and the female behaviour was video recorded for $20 \mathrm{~min}$. The time spent in the preference zone, the frequency, duration and latency of courtship behaviour and the female swimming activity were measured. Position in the aquarium and behavioural responses were quantified using The Observer PC Software V3.0 (Noldus Information Technology, Wageningen, The Netherlands).

During acclimation and also during the test, control water flowing from $\mathrm{T}_{\text {control }}$ entered the central compartment through the water connection close to the stimulus male compartment and left through the opening on the top-opposite side.

After being tested the female and the male were returned to their stock tanks. The central compartment was emptied and cleaned according to the previously described method. The central compartment was refilled and the same female placed in the acclimation area for another $5 \mathrm{~min}$.

\section{Treatment $K$ : control}

The procedure was similar to the one previously described except that no male was presented. The preference zone was defined as the one adjacent to the control water inflow.

\section{Treatment $C$ : chemical}

After the acclimation period, water flowing from $T_{\text {control }}$ to the central compartment was replaced by water flowing from $T_{\text {chemical }}$. This connection to $T_{\text {chemical }}$ was performed simultaneously with the removal of the opaque screens. The procedure was otherwise similar to treatment $\mathrm{K}$.

\section{Treatment $C V$ : chemical+visual}

The procedure was similar to treatment $\mathrm{C}$, but the male used in treatment $\mathrm{V}$ was also presented as a visual stimulus. 


\section{EXPERIMENTAL DESIGN}

The four treatments were presented sequentially to each female. Eight different sequences of presentation orders were defined by two orthogonal $4 \times 4$ Latin squares. As 24 females were tested, the same presentation order was replicated three times. On each experimental day four females were tested. One male was used as a source of visual stimuli for these four females while another male was used a source of chemical stimuli. In the following experimental day another four females were tested and a different pair of males was used. The four different presentation orders, within the same Latin square, were randomly assigned to these four females. The stimulus was presented in the left lateral compartment to two of these females and in the right lateral compartment to the other two. A total of six males were used as visual stimulus $\left(L_{\mathrm{S}}, 10.8 \pm 0.3 \mathrm{~cm}\right.$, range $9.9-11.7 \mathrm{~cm})$ and six as a source of chemical stimulus $\left(L_{\mathrm{S}}, 11.3 \pm 0.3 \mathrm{~cm}\right.$, range $10 \cdot 4-12 \cdot 5 \mathrm{~cm})$ throughout the experiment.

Most of the data did not conform to the assumptions for parametric analysis. Accordingly, and unless stated otherwise, data were analysed using the non-parametric Friedman ANOVA test calculated with the aid of Statistica v.5.0A (Statsoft Inc., U.S.A.). When differences were statistically significant, the Nemenyi's post hoc test was applied. All $P$ values are two-tailed.

\section{RESULTS}

\section{ENTRANCE IN THE PREFERENCE ZONE}

After acclimation females in the central compartment could either enter the preference zone or the opposite area of similar size. Of the 24 tested females, 18 first entered the preference zone in treatment $\mathrm{CV}, 16$ in treatment $\mathrm{C}, 13$ in treatment $\mathrm{V}$ and 12 in treatment $\mathrm{K}$ (Cochran q test: $Q_{3}=6 \cdot 35, P=0 \cdot 096$ ). There was no difference among treatments in the latency of entrance in the preference zone (Friedman ANOVA: $P>0 \cdot 05$ ).

\section{COURTSHIP}

Twenty-one females courted the male in treatment CV and 19 in treatment V. Females only performed courtship displays inside the preference zone and at a short distance $(2-7 \mathrm{~cm})$ from the visual stimulus male. The frequency, duration and latency of the courtship displays did not differ between treatment $\mathrm{CV}$ and $\mathrm{V}$ (Friedman ANOVA on the four treatments, frequency: $\chi^{2}=52 \cdot 39$, d.f. $=3$, $P<0.001$; Nemenyi's post hoc test: CV v. V, NS; duration: $\chi^{2}=52.45$, d.f. $=3, P<0 \cdot 001$; Nemenyi's post hoc test: CV v. V, NS; latency: $\chi^{2}=48 \cdot 09$, d.f. $=3, P<0 \cdot 001$; Nemenyi's post hoc test: CV $v$. V, NS). The results from treatments $\mathrm{K}$ and $\mathrm{C}$ were not compared with treatments $\mathrm{V}$ and $\mathrm{CV}$ because only one female performed one courtship display in the absence of the visual stimulus (treatment C).

\section{TIME SPENT IN THE PREFERENCE ZONE}

No difference was recorded in the time spent in the preference zone between the four treatments $(P>0 \cdot 05$, NS, Table I). Females spent significantly more time in the preference zone than in the corresponding opposite area of the central compartment in all treatments (Wilcoxon signed ranks test: treatment $\mathrm{V}, z=3 \cdot 00$, $n=24, P<0 \cdot 01$; treatment $\mathrm{K}, z=3 \cdot 40, n=24, P<0 \cdot 01$; treatment C, $z=3 \cdot 03, n=24$, $P<0 \cdot 01$; treatment CV, $z=2 \cdot 07, n=24, P<0 \cdot 05$, Table I). 
TABLE I. Behavioural measures (mean \pm S.E.) of female $S$. pavo when exposed to the four different treatments $(n=24)$

\begin{tabular}{lcccc}
\hline & $\begin{array}{c}\text { Time in the } \\
\text { preference zone } \\
\text { (s) }\end{array}$ & $\begin{array}{c}\text { Time in the } \\
\text { opposite zone } \\
\text { (s) }\end{array}$ & $\begin{array}{c}\text { Time } \\
\text { swimming } \\
(\mathrm{s})\end{array}$ & $\begin{array}{c}\text { Latency of the } \\
\text { first swim } \\
\text { (s) }\end{array}$ \\
\hline Visual & $594 \pm 52$ & $301 \pm 35$ & $778 \pm 50$ & $20 \pm 8$ \\
Control & $548 \pm 44$ & $292 \pm 37$ & $726 \pm 57$ & $19 \pm 5$ \\
Chemical & $550 \pm 45$ & $306 \pm 35$ & $776 \pm 44$ & $21 \pm 8$ \\
Chemical+ visual & $525 \pm 52$ & $336 \pm 40$ & $734 \pm 55$ & $25 \pm 10$ \\
\hline
\end{tabular}

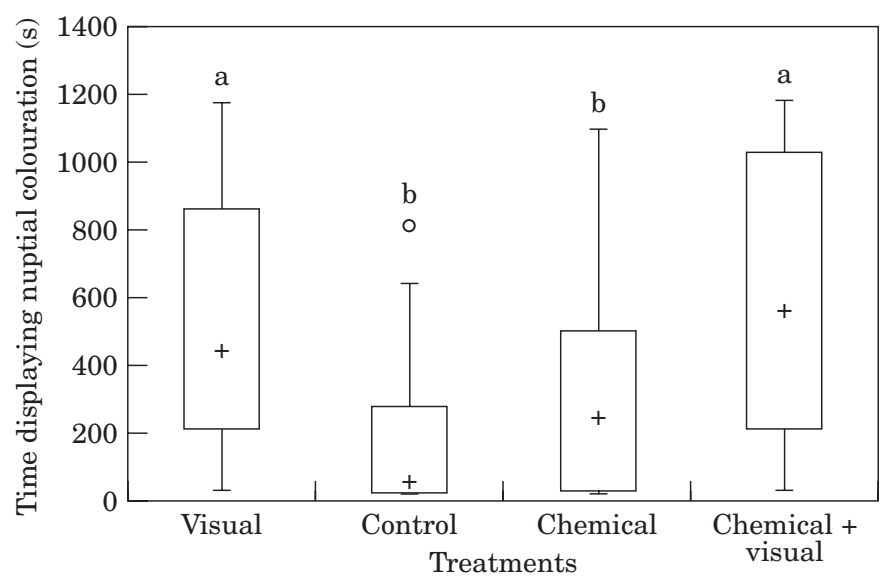

FIG. 2. Time spent by females displaying the nuptial colouration in the four treatments. Whiskers, non-outlier limits; box, 25-75\%; + median; $\bigcirc$, outliers. Different letters indicate groups with statistically significant differences $(P<0 \cdot 05) . \quad n=24$.

\section{NUPTIAL COLOURATION}

More females displayed the nuptial colouration when a male was visible. Twenty-one females displayed the nuptial colouration in treatment $\mathrm{CV}, 20$ in treatment V, 7 in treatment $\mathrm{C}$ and 6 in treatment $\mathrm{K}$ (Cochran q test: $Q_{3}=34 \cdot 76$, $P<0 \cdot 001)$. The time spent by females exhibiting the nuptial colouration was significantly higher in treatments $\mathrm{V}$ and $\mathrm{CV}$ than in treatments $\mathrm{K}$ and $\mathrm{C}$ $\left(\chi^{2}=36.98\right.$, d.f. $=3, P<0.001$; Nemenyi's post hoc test: V v. K, $P<0.001$; V v. C, $P<0.05$; K v. CV, $P<0.001 ; \mathrm{C}$ v. CV, $P<0.01$, Fig. 2), but there were no statistically significant differences between treatments $\mathrm{K}$ and $\mathrm{C}$ or between treatments $\mathrm{V}$ and $\mathrm{CV}$ (Fig. 2).

\section{SWIMMING ACTIVITY}

The overall time spent swimming by test females did not differ among treatments $(P>0.05$, Table I). The latency time for the first swim after removing the opaque screens was also similar among treatments $(P>0 \cdot 05$, Table I). 
TABLE II. Spearman-rank correlations and level of significance between female courtship behaviours displayed across the four treatments and the day they were tested ( $n=24$ for all variables)

\begin{tabular}{lrr}
\hline & \multicolumn{2}{c}{ Test day } \\
\cline { 2 - 3 } & \multicolumn{1}{c}{$r_{s}$} & \multicolumn{1}{c}{$P$} \\
\hline Time displaying the nuptial colouration (across all treatments) & -0.65 & $<0.001$ \\
Frequency of the nuptial colouration displays (across all treatments) & -0.67 & $<0.001$ \\
Latency of the first nuptial colouration display (across all treatments) & 0.31 & $=0.15$ \\
Time displaying the courtship behaviour (across all treatments) & -0.58 & $<0.01$ \\
Frequency of the courtship behaviour displays (across all treatments) & -0.46 & $<0.05$ \\
Latency of the first courtship behaviour (across all treatments) & 0.42 & $<0.05$ \\
Degree of belly distension & -0.57 & $<0.01$ \\
\hline
\end{tabular}

\section{MALE TRAITS}

A test was made of whether two possible traits assessed by females during visual trials, male body size and crest size, were related to female sexual behaviour. As four females were presented to the same male, the average of the behavioural scores received by each male from these females during visual trials (V) was considered. The relative size of the male's crest correlated with the time spent by females courting (Spearman rank correlation: $r_{\mathrm{s}}=0 \cdot 97, n=6, P=0 \cdot 001$ ) and with the time displaying the nuptial colouration $\left(r_{\mathrm{s}}=0.79, n=6, P=0.059\right)$. No relation was found between female courtship behaviours and male body size (time spent courting, $P=0 \cdot 741$; time displaying nuptial colouration, $P=0 \cdot 425$ ).

\section{TEMPORAL VARIATION}

Females were tested on six different days from the 19 June to 19 July 1999. Females tested later in the breeding season displayed the nuptial colouration and courted the males with a lower frequency and duration and a higher latency (Table II). The degree of female belly distension, an indicator of the degree of ripeness, was negatively correlated with the day of the test (Table II).

\section{DISCUSSION}

Female $S$. pavo courtship behaviour was elicited by male visual cues but not by chemical cues. A courtship event occurred only once when a male was not visible, while 290 courtship acts were recorded during treatments $\mathrm{CV}$ and V. Furthermore, chemical cues did not influence female courtship frequency, duration or latency. Visual contact with a male was sufficient to elicit the full range of female courtship behaviour, and courtship displays always occurred at a short distance from the male. Although some females displayed the nuptial colouration in control and chemical treatments, the frequency and duration of this behaviour when a male was visible was much higher.

The relative size of the male's crest correlated with the time spent by females courting and displaying the nuptial colouration, suggesting a signalling function for this trait. Corroborating this hypothesis, in a previous simultaneous choice 
experiment it was demonstrated that females prefer males with larger crests (D. Gonçalves \& R. Oliveira, unpubl. data).

No relation was found between male body size and female sexual behaviour. Interestingly, previous field studies have failed to find any relation between the development of the crest and male reproductive success (Oliveira et al., 1999; Gonçalves et al., 2002), although larger males have been shown to be more successful in nature (Oliveira et al., 1999; Gonçalves et al., 2002). The present results suggest that one of the traits assessed by females during sexual interactions is the head crest. In nature, males spent the majority of time with their head protruding from the nest while most of their body was inside (Oliveira et al., 1999; Gonçalves et al., 2002). Thus, the traits visually available for females to assess males should be located on the head. The fact that larger males had a higher reproductive success in natural populations was probably due to the strong male-male competition for nests, with larger males having access to better nest sites, and not to female preference for larger males. The reversal of sex-roles, observed in this population, with males being more choosy than females, may dilute the effect of female preference for males with larger crests, explaining the absence of correlation between male reproductive success and crest size in previous field studies.

In all treatments females spent more time in the preference zone, close to the water inflow, but this was not related to a specific visual or chemical stimulus since neither increased the time spent in the preference zone by females. When offered the chemical stimulus, a slightly higher number of females first entered the preference zone compared to the control and visual stimulus only treatments, although this difference was not statistically significant. Female reothatic attraction to the water inflow observed in all treatments could have masked the attractant properties of the male's holding water, which has been demonstrated in previous experiments (Laumen et al. 1974; Zeeck \& Ide, 1996; Barata et al., 2002).

The fact that females did not exhibit courtship behaviours when only the chemical stimulus was presented is in apparent contradiction with the results reported by Zeeck \& Ide (1996). In their experiment females were reported to display sexual behaviour in the presence of male chemical cues alone. Although the fish used in their study also originated from the south Portuguese coast, the study differed in other respects from the one presented here. Female display behaviour was described as ' bending of the body by $90^{\circ}$, quivering', which is not the accepted courting behaviour of the species, which entails quick flickering of the pectoral fins while opening and closing the mouth in synchrony, and turning the belly sideways towards the male (Fishelson, 1963; Patzner et al., 1986; Almada et al., 1995; Gonçalves et al., 1996). Quivering is normally associated with spawning and in the study of Zeeck \& Ide (1996) the presence of nest-like tubes allowing female access to the compartment with the male chemical stimulus may have triggered spawning attempts in ripe females. In the present experiment females never exhibited quivering. In the study of Zeeck \& Ide (1996), up to three females were simultaneously used in a test and display behaviour by one female could facilitate (social facilitation; Shennan et al., 1994) display behaviour (and spawning) by the other females, thus 'inflating' the results. It is particularly difficult to evaluate the significance of their findings as 
no indication on the number of females used was given and no results of statistical analysis were provided.

In other experiments females also failed to exhibit courtship behaviours in the presence of chemical cues alone, corroborating the results presented here (Laumen et al. 1974; Barata et al., 2002).

In conclusion, the results show that male visual cues were enough to elicit the full range of female courtship behaviour and that male chemical cues by themselves or in conjunction with visual cues did not elicit any significant or additional behavioural response. Thus, chemical substances released by $S$. pavo males were not part of a multicomponent signal used to elicit female courtship behaviour. Most likely, the relative importance of male visual and chemical cues will vary with context. For $S$. pavo females, male chemical cues with attractant properties (Laumen et al., 1974; Patzner \& Seiwald, 1987; Zeeck \& Ide, 1996; Barata et al., 2002) may be indicative of the presence of a sexual partner at a distance, while male visual cues are probably assessed during female mate choice. Alternatively, chemical cues may be used by females in their ultimate decision to spawn, which could explain why in the study of Zeeck \& Ide (1996) females spawned in the presence of chemical cues alone.

During the experiment, females progressively decreased the frequency of nuptial colouration and courtship displays and increased the latency to display sexual behaviours, which reflects a lower motivation to spawn towards the end of the breeding season. In accordance, their bellies were less distended towards the end of the experiment reflecting a lower gonadosomatic index, as found by Gonçalves \& Almada (1997). Future female mate choice experiments should consider this decrease in female sexual motivation as the breeding season proceeds.

The authors wish to thank the Ria Formosa Nature Park, especially its director L. Fonseca, for providing essential logistical and technical support, J. Reis (Centro de Ciências do Mar do Algarve, Faro) for technical support and advice and J. Bacelo for helping in the experiments. The work was funded by Fundação para a Ciência e a Tecnologia (UI\&D 331/94; grant PRAXIS/P/BIA/11157/98). During this study D.M.G. was supported by a Praxis XXI Ph.D. grant (BD/13436/97).

\section{References}

Almada, V. C., Gonçalves, E. J., Oliveira, R. F. \& Santos, A. J. (1995). Courting females: ecological constraints affect sex roles in a natural population of the blenniid fish, Salaria pavo. Animal Behaviour 49, 1125-1127.

Almada, V. C., Gonçalves, E. J., Santos, A. J. \& Baptista, C. (1994). Breeding ecology and nest aggregations in a population of Salaria pavo (Pisces: Blenniidae) in an area where nest sites are very scarce. Journal of Fish Biology 45, 819-830.

Barata, E. N., Nogueira, R., Serrano, R., Gomes, L. \& Canário, A. V. M. (2002). A pheromonal role for the anal gland of male peacock blennies (Salaria pavo) in female attraction. Comparative Biochemistry and Physiology A 132, S64-S65.

Bradbury, J. \& Vehrencamp, S. (1998). Principles of Animal Communication. Sunderland: Sinauer Associates, Inc.

Fishelson, L. (1963). Observations on littoral fishes of Israel. I. Behaviour of Blennius pavo Risso (Teleostei: Blenniidae). Israel Journal of Zoology 12, 67-80.

Gonçalves, E. J. \& Almada, V. C. (1997). Sex differences in resource utilization by the peacock blenny. Journal of Fish Biology 51, 624-633. 
Gonçalves, E. J., Almada, V. C., Oliveira, R. F. \& Santos, A. J. (1996). Female mimicry as a mating tactic in males of the blenniid fish Salaria pavo. Journal of the Marine Biological Association of the United Kingdom 76, 529-538.

Gonçalves, D. M., Simôes, P. C., Chumbinho, A. C., Correia, M. J., Fagundes, T. \& Oliveira, R. F. (2002). Fluctuating asymmetries and reproductive success in the peacock blenny. Journal of Fish Biology 60, 810-820.

Laumen, J., Pern, U. \& Blüm, V. (1974). Investigations on the function and hormonal regulations of the anal appendices in Blennius pavo. Journal of Experimental Zoology 190, 47-56.

Oliveira, R. F., Almada, V. C., Forsgren, E. \& Gonçalves, E. J. (1999). Temporal variation in male traits, nest aggregations and mating success in the peacock blenny, Salaria pavo. Journal of Fish Biology 54, 499-512.

Papaconstantinou, C. A. (1979). Secondary sex characters of Blennioid fishes (Pisces: Blenniidae). Thalassografica 1, 57-75.

Patzner, R. A. \& Seiwald, M. (1987). The reproduction of Blennius pavo. II. Secondary sexual organs and accessory glands of the testis during the reproductive cycle. In Proceedings of the Fifth Congress of European Ichthyologists (Kullander, S. \& Fernholm, B., eds), pp. 293-298. Stockholm: Swedish Museum of Natural History.

Patzner, R. A., Seiwald, M., Adlgasser, M. \& Kaurin, G. (1986). The reproduction of Blennius pavo. V. Reproductive behaviour in natural environment. Zoologisches Anzeiger 216, 338-350.

Rowe, C. (1999). Receiver psychology and the evolution of multicomponent signals. Animal Behaviour 58, 921-931.

Shennan, M. G. C., Waas, J. R. \& Lavery, R. J. (1994). The warning signals of parental convict cichlids are social facilitated. Animal Behaviour 47, 974-976.

Zander, C. D. (1986). Blenniidae. In Fishes on the North-Eastern Atlantic and the Mediterranean (Whithead, P. J. P., Bauchot, M. L., Hureau, J. C., Nielsen, J. \& Tortonese, E., eds), pp. 1096-1112. Paris: Unesco.

Zeeck, E. \& Ide, V. (1996). The role of sex pheromones in the reproductive behaviour of Blennius pavo (Risso). In Fish Pheromones: Origins and Mode of Action (Canário, A. V. M. \& Power, D., eds), pp. 33-38. Faro: University of Algarve. 